\title{
Investigation into the Effect of Mold Temperature on the Fatigue Deflection of Clasps of Commercially Pure Titanium: An In Vitro Study
}

\author{
Aashritha Shenava ${ }^{1}$, Roselene Meshramkar ${ }^{2}$
}

\begin{abstract}
Aim: The aim of the study was to evaluate the effect of mold temperature [room temperature $\left(32^{\circ} \mathrm{C}\right), 450^{\circ} \mathrm{C}$, and $790^{\circ} \mathrm{C}$ ] on the fatigue deflection of clasps of commercially pure titanium.

Materials and methods: Forty-five retentive wax profiles were cast in molds having three different mold temperature [room temperature $\left(32^{\circ} \mathrm{C}\right)$, $450^{\circ} \mathrm{C}$, and $790^{\circ} \mathrm{C}$. Specimens of grade 4 titanium, following the eligibility criteria, were selected. A 2-mm deflection test was done using an Instron machine and the flexibility of clasps of the respective groups was calculated. Deflection fatigue was tested using a cyclic-loaded custommade oscillating machine by calculating the number of loading cycles required to fracture the specimen.

Results: The mean of flexibility of the clasp bars was observed and the difference was significant (between groups, $F$ value was 38.49 at $p$ $=0.0000$ and within groups at $p \leq 0.01$, respectively). The number of loading cycles applied to the clasp bars casted with $450^{\circ} \mathrm{C}$ and room temperature was more than that of $790^{\circ} \mathrm{C}$, suggesting that the fatigue strength of clasps casted at $450^{\circ} \mathrm{C}$ and room temperature is more than that at $790^{\circ} \mathrm{C}$. The mean of loading cycles of the clasp bars was observed and the difference was significant. Between groups, $F$ value was 11.89 at $p=0.0001$ and within groups at $p \leq 0.01$.

Conclusion: The number of loading cycles applied to the clasp bars casted with $450^{\circ} \mathrm{C}$ and room temperature was more than that of $790^{\circ} \mathrm{C}$, and this suggests that the fatigue strength at $450^{\circ} \mathrm{C}$ and room temperature is more than that at $790^{\circ} \mathrm{C}$. Temperature has an important role to play as the modulus of elasticity is higher at room temperature and $450^{\circ} \mathrm{C}$ than that at $790^{\circ} \mathrm{C}$.

Clinical implication: The ideal temperature for a titanium casting with relatively high fatigue strength would be $450^{\circ} \mathrm{C}$ mold temperature or room temperature. By investigating the fatigue deflection, it is clear that a desired undercut should be planned before clasp designing, considering the metal to be used.

Keywords: Casting technique, Flexural strength, Mold temperature.

World Journal of Dentistry (2020): 10.5005/jp-journals-10015-1691
\end{abstract}

\section{INTRODUCTION}

Fatigue is the loss of mechanical properties of materials after repeated loading. ${ }^{1}$ It is influenced by many factors including the quality of surface, metallographic microstructure, and presence of internal defects. The clasp of a removable partial denture undergoes fatigue during constant deflection of the clasp during insertion and removal over the undercut of the teeth. ${ }^{2}$

Titanium is very reactive at high temperature, is easily oxidized, and reacts with investment components. The mold temperature is an important factor that affects the quality of titanium castings. The thickness of the surface reactive layer has been reported to be about $85 \mu$ at room temperature, $120 \mu$ at $850^{\circ} \mathrm{C}$, which in turn alters the physical and chemical properties of titanium. ${ }^{3,4}$

Although fatigue fracture can occur in a highly polished specimen, the crack initiation procedure is facilitated by surface roughness and irregularities. ${ }^{5}$ Kenneth stated that most prosthetic and restoration fractures develop progressively over many stress cycles after initiation of a crack from a critical flaw and subsequently by propagation of the crack, until an unexpected fracture occurs. ${ }^{6}$ Stress values well below the ultimate tensile stress can produce premature fracture of the dental prosthesis because microscopic flaws grow slowly over many loading cycles of stress, and this phenomenon is called fatigue failure. Fatigue failure is determined by subjecting a material to cyclic stress of a maximum known value and determining the number of loading cycles that are required
${ }^{1}$ Department of Prosthodontics, AB Shetty Memorial Institute of Dental Sciences, Mangaluru, Karnataka, India

${ }^{2}$ Department of Prosthodontics, SDM College of Dental Sciences and Hospital, Dharwad, Karnataka, India

Corresponding Author: Aashritha Shenava, Department of Prosthodontics, AB Shetty Memorial Institute of Dental Sciences, Mangaluru, Karnataka, India, Phone: +91 9448457403, e-mail: draashrithashenava@nitte.edu.in

How to cite this article: Shenava A, Meshramkar R. Investigation into the Effect of Mold Temperature on the Fatigue Deflection of Clasps of Commercially Pure Titanium: An In Vitro Study. World J Dent 2020;11(1):69-74.

Source of support: Nil

Conflict of interest: None

to produce it. The stress distribution may depend on the elastic modulus of the alloy, dimensions and curvature of the clasp, and the amount of deflection in relation to the abutment undercut. ${ }^{7}$

Deterrents to the use of titanium in dentistry have been its high melting temperature $\left(1,670^{\circ} \mathrm{C}\right)$ and reactivity, rendering the casting operation very difficult and necessitating special melting procedures, mold material, and equipment. ${ }^{8,9}$ The mold temperature affects the reaction of the metal with the investment material. ${ }^{10}$ The variation in the temperature of the casting ring at the 
time of flow of molten metal may cause solidification, which may result in different magnitude and direction of the casting shrinkage along with inaccuracy of casting due to various degrees of thickness of surface reactive layer, which affects the strength of the material. ${ }^{11}$ The deflection is important as the clasps bend minimum 10 times per day due to insertion and removal and leads to its dislodgment occasionally. ${ }^{12}$ Such repeated deflection may induce fatigue into the clasp arm, leading to its fracture. The fracture of the clasp arm may be precipitated by the internal artifacts such as porosity and formation of hard layer on the surface due to high temperature of the molten titanium (liquidus temperature) casting in contact with mold walls having too low temperature. ${ }^{13}$

It has been reported that higher mold temperature may affect the mechanical properties especially fatigue deflection of cast titanium. ${ }^{4}$ In the present study, the effect of the mold temperature (room temperature, $450^{\circ} \mathrm{C}$, and $790^{\circ} \mathrm{C}$ ) on fatigue deflection of cast clasps was evaluated and compared. The number of loading cycles required to fracture the clasps at three different mold temperatures was also checked.

\section{Materials and Methods}

This was an in vitro experimental study done at the Department of Prosthodontics SDM College of Dental Sciences, Dharwad. Prefabricated 45 straight tapered half-round wax profiles $(0.08$ $\mathrm{mm}$ in diameter and $3.2 \mathrm{~cm}$ in length, Dentarum, Germany) were used for this study (Fig. 1). The liquid and powder ratio used is $45 \mathrm{~mL}: 100 \mathrm{~g}$ which is weighed using an electronic balance (Multivac 4-degussa Germany). Phosphate-bonded silica investment (Titek GMG-Oratig, Italy) was used as the investment material for the three groups of wax profiles of 15 each.

\section{Burnout and Cooling Regime}

The temperature of the burnout machine with three casting molds of 15 wax profiles each was gradually increased from room temperature to $450^{\circ} \mathrm{C}$. It was held at $450^{\circ} \mathrm{C}$ for 30 minutes before heating to $950^{\circ} \mathrm{C}$. The first mold was cooled in the burnout machine and casted at $790^{\circ} \mathrm{C}(\mathrm{GC})$ and casting was done. The second was cooled to $450^{\circ} \mathrm{C}(\mathrm{GB})$ followed by casting and the third mold was cooled at room temperature (GA) and casted. The castings were done in Titec F210 M semiautomatic casting machine under 4 bar pressure of argon (inert argon gas atmosphere to prevent excessive

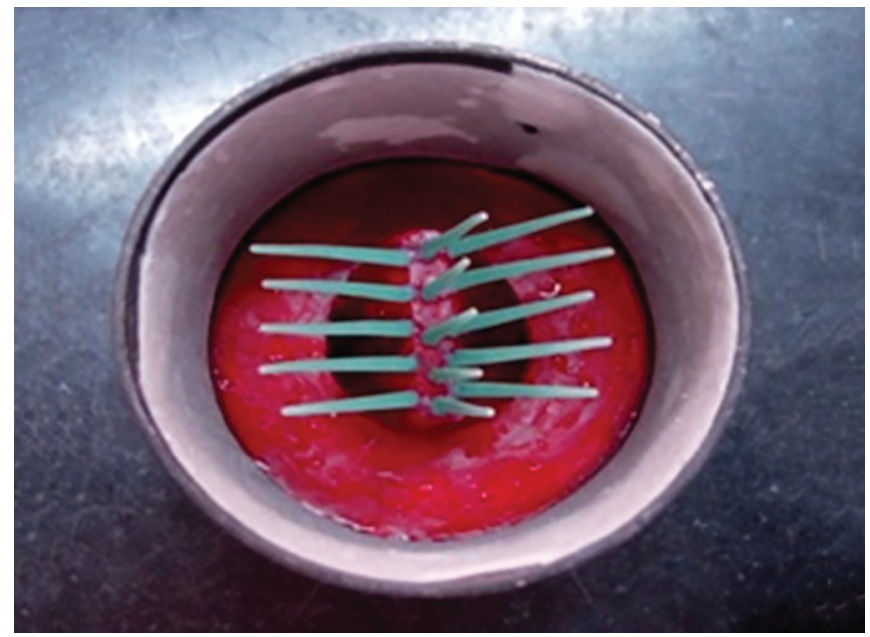

Fig. 1: Preformed wax profiles attached to the sprue former reaction of the molten titanium with oxygen in the atmosphere). Commercially pure grade 4 titanium (N2-0.04\%, C- $0.02 \%$, $\mathrm{H} 2-0.0030 \%, \mathrm{Fe}-0.10 \%$, and $\mathrm{Ti}-99.5370 \%)$ was used. Grade 4 titanium was used with thermal conductivity $20.1 \mathrm{~W} / \mathrm{m} \mathrm{K}$, elongation $15 \%$, density $4.5 \mathrm{~g} / \mathrm{cm}^{3}$, modulus of elasticity $104 \mathrm{GPa}$, and tensile strength $550 \mathrm{MPa} .{ }^{14}$ The casted samples were surface polished using titanium polishing kit (Rematitan) to remove the surface nodules without removing the outer layer and were sandblasted. All clasps were subjected to radiographic evaluation, i.e., out of 45 clasps 6 clasps from GA, 5 clasps from GB, and 8 clasps from GC revealed large porosities and nodules (Fig. 2). They were replaced in their respective groups and subjected to loading.

The flexibility of the clasps casted at room temperature (FA), $450^{\circ} \mathrm{C}(\mathrm{FB})$, and $790^{\circ} \mathrm{C}(\mathrm{FC})$ was calculated using the formula: flexibility $=$ displacement $(\mathrm{mm}) / \mathrm{load}(\mathrm{Kgf})$. For the purpose of testing the fatigue deflection, the clasps were deflected to $2 \mathrm{~mm}$ and the load was noted using a universal testing machine (Instron Digital 4467 series) (Fig. 3). The clasps were subjected to cyclic loading using a modified custom-made oscillating cutting machine tool (Model CD301 370 W Type1 Black and Decker 50 Hz, 3,100/ minutes), which was fixed on a table top, with a custom-made jig having a spring-loaded device to return the clasp to its original position (Fig. 4).

Vertical level of the hitting head was adjusted, so that it resulted in $5 \mathrm{~mm}$ deflection of the clasp. A stop watch was used to note the time required till the clasp bars fractured. The time taken multiplied by the oscillating cycles/min resulted in the loading cycles required to fracture the clasp.

\section{Statistical Analysis}

Statistical analysis was performed using SPSS—version 17.0. Data were subjected to statistical analysis of multiple comparisons (Tukey test) and analysis of variance (ANOVA).

\section{Results}

The mean flexibility of FA, FB, and FC is $1.320 \pm 0.3468,1.307 \pm$ 0.1751 , and $2.427 \pm 0.5763$, respectively. Data showed maximum value of flexibility with respect to clasp bars cast at $790^{\circ} \mathrm{C}$ and minimum value of flexibility with respect to clasp bars casted at $450^{\circ} \mathrm{C}$ (Table 1 ).

It has been found that the difference was significant when the mean flexibility of the clasp bars was subjected to ANOVA (between groups, $F$ value was 38.49 at $p=0.0000$ and within groups at $p \leq$ 0.01 , respectively (Table 2 ). The Tukey's test showed a significant difference in flexibility between FA and FC as well as FB and FC (Table 3). The mean number of loading cycles required to fracture $\mathrm{GA}, \mathrm{GB}$, and $\mathrm{GC}$ is $6,351 \pm 1,627,6,111 \pm 1,578$, and 3,996 $\pm 1,101$, respectively (Table 4$)$. The data showed wide range of loading cycles with maximum value of loading cycles with respect to clasp bars casted in room temperature and minimum value of loading cycles with respect to clasp bars casted at $790^{\circ} \mathrm{C}$ mold temperature.

It was observed that the difference was significant between groups when the mean loading cycles of the clasp bars was subjected to ANOVA, $F$ value was 11.89 at $p=0.0001$ and within groups at $p \leq 0.01$, respectively (Table 5 ). A significant difference was observed in loading cycles between room temperature and at $790^{\circ} \mathrm{C}$ as well as $450^{\circ} \mathrm{C}$ and $790^{\circ} \mathrm{C}$ when Tukey's test was used to test multiple comparisons of the loading cycles at room temperature, $450^{\circ} \mathrm{C}$, and $790^{\circ} \mathrm{C}$ (Table 6). 

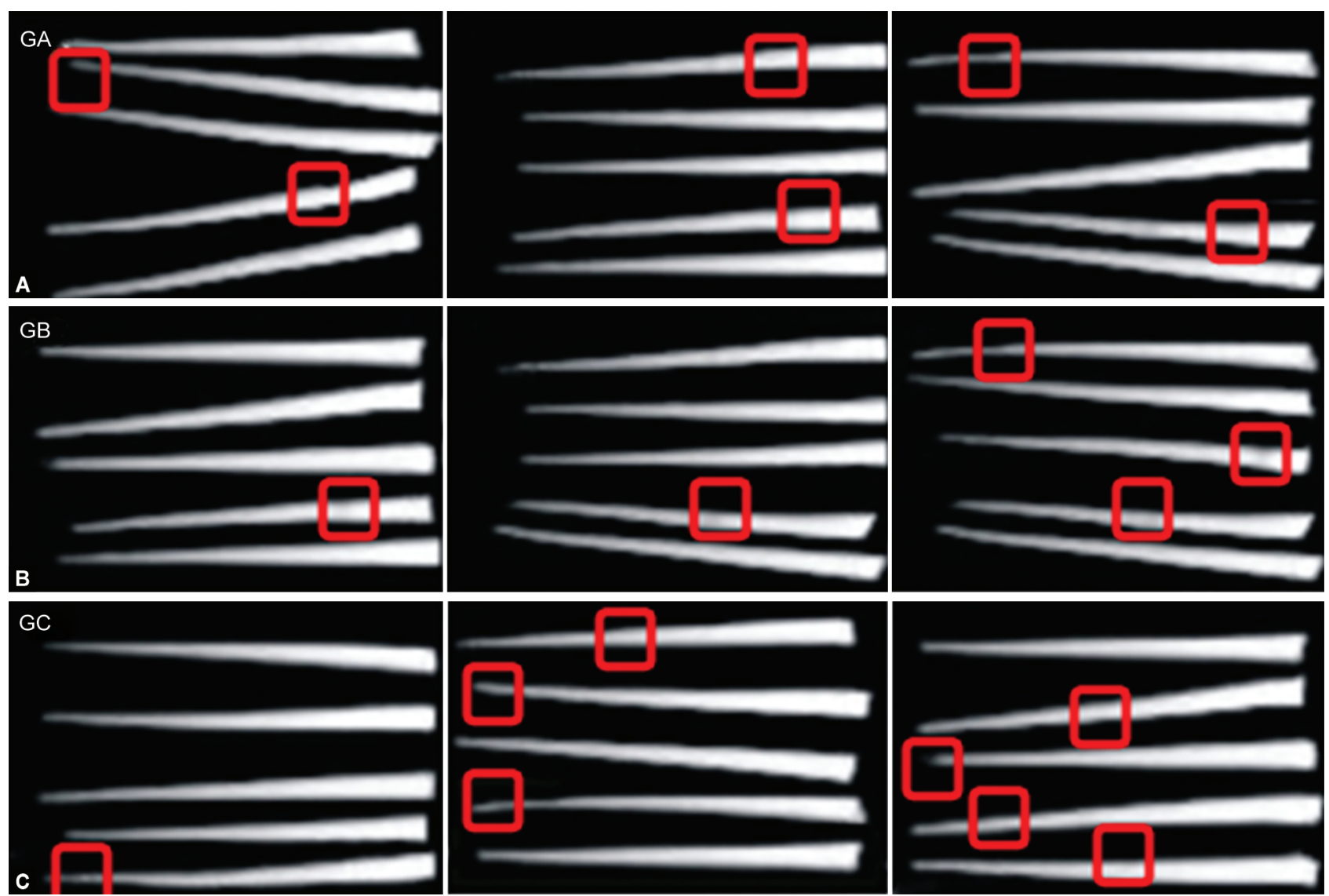

Figs 2A to C: (A) Radiographs of clasps casted at room temperature (GA). Radiolucent areas circled; (B) Radiographs of clasps casted at $450^{\circ} \mathrm{C}$ (GB). Radiolucent areas circled; (C) Radiographs of clasps casted at $790^{\circ} \mathrm{C}$ (GC). Radiolucent areas circled

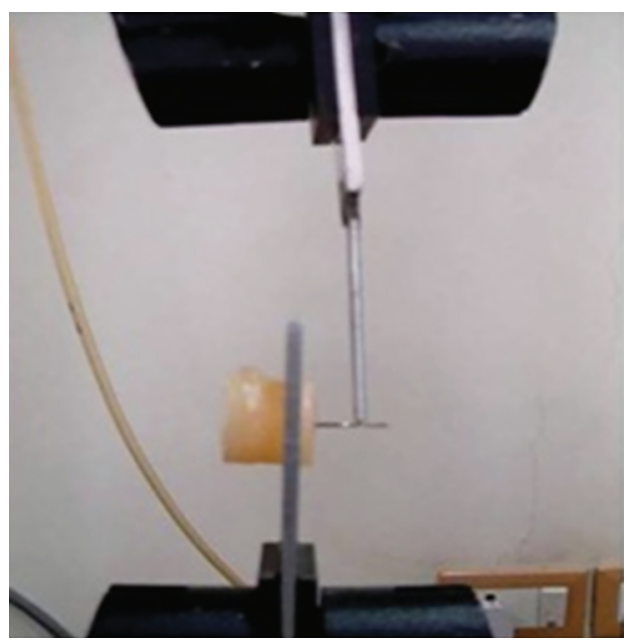

Fig. 3: Cast clasp mounted on universal testing machine

\section{Inference of the Study}

In the present study, the titanium clasps casted at room temperature and at $450^{\circ} \mathrm{C}$ had more fatigue strength compared to the clasps casted at $790^{\circ} \mathrm{C}$. This was substantiated by the mean loading cycles required to fracture the clasps at room temperature, $450^{\circ} \mathrm{C}$, and $790^{\circ} \mathrm{C}$ which are 3,654-8,650, 3,100-8,212, and 2,597-5,910, respectively. Thus, the mold temperature has a direct effect on the fatigue strength of the casted titanium clasps.

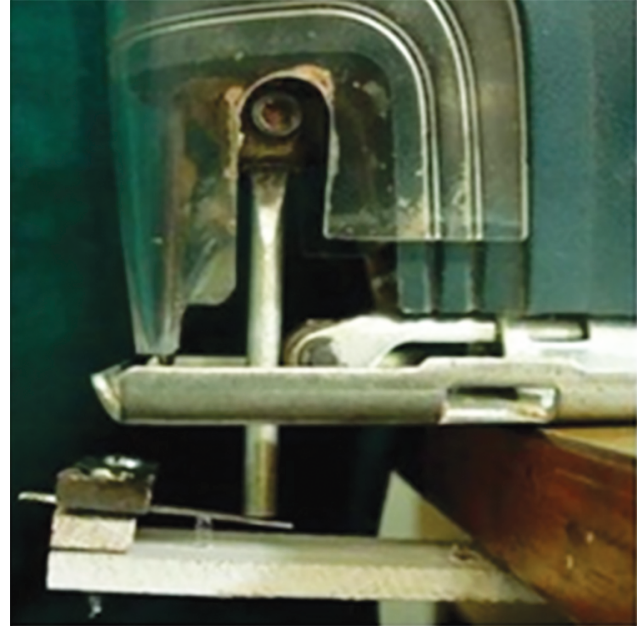

Fig. 4: Closeup of cast mounted on custom-made oscillation machine (Black and Decker)

\section{Discussion}

The loss of retention of removable partial denture during insertion and removal of the denture affects the clasp by causing metal fatigue. ${ }^{5,15}$ The constant deflection of the retentive arm of the clasp affects the physical properties mainly the flexibility. As the number of deflection increases, it has been shown that the deflection fracture strength decreases for titanium; therefore, deflection 
Table 1: Mean and standard deviation of flexibility of the clasp bars using commercially pure titanium

\begin{tabular}{lllll}
\hline Group & Mean & $S D$ & $S E$ & Range min-max \\
\hline Room temperature (FA) & 1.320 & 0.3468 & 0.08955 & $1.1-2.5$ \\
$450^{\circ} \mathrm{C}(\mathrm{FB})$ & 1.307 & 0.1751 & 0.04522 & $1.0-1.6$ \\
$790^{\circ} \mathrm{C}(\mathrm{FC})$ & 2.427 & 0.5763 & 0.01488 & $1.6-3.3$ \\
\hline
\end{tabular}

$\mathrm{SD}$, standard deviation; $\mathrm{SE}$, standard error

The number of loading cycles required to fracture the cast clasps was calculated using the equation-Time required to fracture the clasp $\times$ the number of cycles per minute ( 60 seconds)

Table 2: Statistical analysis (one-way analysis of variance) of the mean values of flexibility of the clasp bars using commercially pure titanium

\begin{tabular}{lllllll}
\hline SV & SS & DF & MSS & Fvalue & ${ }^{*} p$ value & Significance \\
\hline Between clasps & 12.40 & 2 & 6.198 & 38.49 & 0.0001 & S \\
Within clasps & 6.763 & 42 & 0.1610 & & & \\
Total & 19.16 & 44 & & & \\
\hline
\end{tabular}

$S$, significance at $5 \%$ level; SV, source of variation, $F$ value, variance ratio; ${ }^{*} p$ value, probability; DF, degree of freedom; MSS, mean sum of squares The number of loading cycles required to fracture the cast clasps was calculated using the equation-Time required to fracture the clasp $\times$ the number of cycles per minute (60 seconds)

Table 3: Multiple comparisons (Tukey test) of the mean value of flexibility of the clasp bars using commercially pure titanium

\begin{tabular}{llcl}
\hline Between groups & & Mean difference & ${ }^{*} p$ value \\
\hline FA & FB & 0.01333 & 0.995 \\
& FC & -1.10667 & 0.000 \\
FB & FC & -1.12000 & 0.000 \\
& FA & 0.01333 & 0.995 \\
FC & FA & -1.10667 & 0.000 \\
& FB & -1.12000 & 0.000 \\
\hline
\end{tabular}

${ }^{*} p$ value, probability

The number of loading cycles required to fracture the cast clasps was calculated using the equation-Time required to fracture the clasp $\times$ the number of cycles per minute ( 60 seconds)

Table 4: Mean and standard deviation of the number of loading cycles to fracture the clasp bars using commercially pure titanium

\begin{tabular}{lllll}
\hline Group & Mean & SD & SE & $\begin{array}{l}\text { Range min- } \\
\max \end{array}$ \\
\hline $\begin{array}{l}\text { Room tem- } \\
\text { perature }\end{array}$ & 6,351 & 1,627 & 420.2 & $3,654-8,650$ \\
$\begin{array}{l}\text { (GA) } \\
450^{\circ} \mathrm{C}(\mathrm{GB})\end{array}$ & 6,111 & 1,578 & 407.4 & $3,100-8,212$ \\
$790^{\circ} \mathrm{C}(\mathrm{GC})$ & 3,996 & 1,101 & 284.3 & $2,597-5,910$ \\
\hline
\end{tabular}

$\mathrm{SD}$, standard deviation; $\mathrm{SE}$, standard error

The number of loading cycles required to fracture the cast clasps was calculated using the equation-Time required to fracture the clasp $x$ Number of cycles per minute ( 60 seconds)

fatigue strength was evaluated in this study (ADA specification no 19.1999). ${ }^{16}$ Deflection of $2 \mathrm{~mm}$ was considered during the loading as it represents maximum activation of retentive arm during insertion and removal of titanium cast partial denture. This was an in vitro study because it is not practical to calculate the force of insertion and removing the removable partial denture in patients.

The flexibility and deflection fatigue strength are affected by grain structure during the solidification of the metal. Fatigue fracture initiation involves the sliding of metal atoms along slip planes within each crystal grain. ${ }^{17}$ The grain structure and the boundaries may be affected by the presence of voids which is a common occurrence in cast titanium structure. ${ }^{18,19}$

In this study, the mold temperature plays an important role in the flexibility of titanium. The mean flexibility of FA, FB, and FC are $1.320 \pm 0.3468,1.307 \pm 0.1751$, and $2.427 \pm 0.5763$, respectively. The castings at room temperature and $450^{\circ} \mathrm{C}$ mold temperature had more strength and thus had resistance to fracture than the castings done at $790^{\circ} \mathrm{C}$ as indicated by the study done by Luo et al. who stated that it is necessary to consider the effect of the mold temperature on the qualities of titanium castings in prosthodontics which were made in clinic. ${ }^{4}$

The test samples (45 clasp bars further divided according to the temperature at which they were casted) were prepared uniformly as mentioned in the materials and method. After casting, it was considered appropriate to take radiographs of titanium clasps since porosities are most common with commercially pure titanium casting. Renata Rodrigues suggested that the porosities might have occurred because of high argon pressure. ${ }^{1}$ Morris et al. suggested that the cause for porosity is inadequate filling of the mold. The other cause may have been the temperature difference between the fluid titanium $\left(1,670^{\circ} \mathrm{C}\right)$ and the mold temperature, which causes rapid solidification of the metal, decreasing the escape of gas from the mold. ${ }^{20,21}$ In this study, porosities were more compared to the clasps casted at $750^{\circ} \mathrm{C}$ which increased the flexibility of the clasps and thus decreased their strength.

The oscillating cutting machine tool (Black and Decker $50 \mathrm{~Hz}$, 3,100 /minutes) is applied to the specimen which replicates the masticatory forces [the force generated during routine mastication is about 70 to 150 newtons ( 16 to $34 \mathrm{lbf}$ ), the maximum masticatory force in some people may reach up to 500 to 700 newtons (110 to $160 \mathrm{lbf}$ )]. Fatigue testing subjected the sample to rapid cycling load until failure occurs. ${ }^{22}$ After each deflection, the force is released and the resiliency of the material returns to its original position unless changes have occurred within the structure. A clasp will be permanently deformed if it is placed into a deep undercut because it will exceed the proportional limit. ${ }^{23}$ To avoid immediate failure, the cylindrical stress generated was within the proportional limit of the component material.

The specimens were only surface polished, leaving a relatively rough surface finish, thus preserved the outer a case layer. The fixed 
Investigation of Mold Temperature on the Fatigue Deflection of Titanium Claps

Table 5: Statistical analysis (one-way analysis of variance) of the mean values of the loading cycles to fracture the clasp bars using commercially pure titanium

\begin{tabular}{lllllll}
\hline SV & SS & DF & MSS & Fvalue & ${ }^{*} p$ value & Significance \\
\hline Between clasps & $50,360,000$ & 2 & $25,180,000$ & 11.89 & 0.0001 & S \\
Within clasps & $88,920,000$ & 42 & $2,117,000$ & & \\
Total & $139,300,000$ & 44 & & & \\
\hline
\end{tabular}

S, significance at $5 \%$ level; SV, source of variation, $F$ value, variance ratio; ${ }^{*} p$ value, probability; DF, degree of freedom; SS, sum of squares; MSS, mean sum of squares

The number of loading cycles required to fracture the cast clasps was calculated using the equation-Time required to fracture the clasp $\times$ the number of cycles per minute ( 60 seconds)

Table 6: Multiple comparison (Tukey test) of the mean value of the loading cycles to fracture the clasp bars using commercially pure titanium

\begin{tabular}{llll}
\hline Between groups & & Mean difference & Significance \\
\hline GA & GB & 240.333 & 0.894 \\
& GC & 2354.267 & 0.000 \\
& GA & -240.333 & 0.894 \\
GC & GC & 2113.933 & 0.001 \\
& GA & -2354.267 & 0.000 \\
& GB & -2113.933 & 0.001 \\
\hline
\end{tabular}

The number of loading cycles required to fracture the cast clasps was calculated using the equation-Time required to fracture the clasp $\times$ the number of cycles per minute ( 60 seconds)

cycling frequency of 3,100/minutes $(50 \mathrm{~Hz})$ was higher than the reported chewing rate (i.e., $1-2 \mathrm{~Hz}$ ). Increased loading rate slightly improves the fatigue resistance of the materials. However, significant effect was observed when the loading frequency was increased. The dimension of the clasp used in the study was $0.8 \mathrm{~mm}$ in diameter which is semicircular and $3.2 \mathrm{~cm}$ in length which tapers toward the tip, this explains the variation in the loading cycles. Lewis and lona et al. suggested that the presence of internal defects could make castings prone to failure in two ways (1) large voids reduce the effective area of the component making it too weak. (2) microporosities can cause stress concentration and become sites of crack initiation. ${ }^{24-26}$ Since quenching (heat hardening treatment) causes change in physical and mechanical properties of a metal or alloy, all samples were cooled at room temperature and not quenched. An important factor that influences the strength is the grain structure. ${ }^{27}$

Thus, the mold temperature ideal for titanium casting is within the range of $450^{\circ} \mathrm{C}$, less porosities are seen, which in turn helps in enhancing the strength of the metal and prevents fracture

\section{Limitations of the study}

- If the oxide layer thickness would have been part of the study, helpful observations might have been obtained to understand better the behavior of the materials

- The data in this study are for straight clasp arms samples in a unidirectional cantilever bending test. A study on curved clasps was not included (care must be exercised with the data of curved clasp-arms because increase in stiffness and decrease in range can be anticipated with decreased radii of curvature).

\section{Conclusion}

The mean number of loading cycles applied to the clasp bars casted with $450^{\circ} \mathrm{C}$ and room temperature was more than that $790^{\circ} \mathrm{C}$, suggesting that the fatigue strength (which is the ability to retain the mechanical properties of the material after repeated loading) of $450^{\circ} \mathrm{C}$ and room temperature is more than $790^{\circ} \mathrm{C}$. The flexibility $(\mathrm{mm} / \mathrm{kgf})$ values are more with regard to room temperature and $450^{\circ} \mathrm{C}$ compared to $790^{\circ} \mathrm{C}$, suggesting that the temperature has an important role to play with fatigue deflection (which is a variable of flexibility) of the commercially pure titanium as the modulus of elasticity is higher with room temperature and $450^{\circ} \mathrm{C}$ compared with the $790^{\circ} \mathrm{C}$ groups.

\section{Clinical Implication}

The ideal temperature for a titanium casting with relatively high fatigue strength would be $450^{\circ} \mathrm{C}$ mold temperature or room temperature. It can be roughly estimated that the clasp bends during insertion and removal of the removable partial denture (RPD) including mastication, which means the clasp is affected by deflection. If no undercuts are given, it may fracture the clasp and also cause wearing of the tooth surface. By investigating the fatigue deflection, it is clear that a desired undercut should be planned before clasp designing, considering the metal to be used. Dentists should evaluate the active clasp length of each flexible clasp arm they design. They should realize that the force required to produce the deflection is an important part of retention of the partial denture.

\section{References}

1. Rodrigues RC, Riberio RF, de MdaMattos G, et al. Comparative study of circumferential clasp retention force for titanium, and cobalt-chromium removable partial dentures. J Prosthet Dent 2002;88(3):290-296. DOI: 10.1067/mpr.2002.128128.

2. Wang RR, Fenton A. Titanium for prosthodontic applications: a review of literature. Quintessence Int 1996;27(6):401-408.

3. Wang RR, Welsch GE, Castro-Cedeno M. Interfacial reactions of cast titanium with mold materials. Int J Prosthodont 1998;11:33-43.

4. Luo X, Gou T, OuYang G. The effect of mold temperature on the mechanical properties and reaction layer structure of the titanium casting. Zhonghua Kou Qiang Yi Xue Za Zhi 1997;32(6):327-330.

5. Vallittu KP, Kokkonen M. Deflection fatigue of cobalt-chromium, titanium and gold alloy cast denture clasp. J Prosthet Dent 1995;74(4):412-419. DOI: 10.1016/S0022-3913(05)80384-1.

6. Kenneth JA. Casting investment and procedure. In: Kenneth JA, Ralph WP, ed. Phillips Science of dental materials, 11th ed., Missouri: Saunders Elsevair; 2003. pp. 295-347.

7. Mahmood A, Wakabayashi N, Takahashi $\mathrm{H}$, et al. Deflection fatigue of ti-6Al-7Nb, Co-Cr, and gold alloy cast clasps. J Prosthet Dent 2005;93(2):183-188. DOI: 10.1016/j.prosdent.2004.11.011.

8. Bezzon OL, Pedrazzi $\mathrm{H}$, Zaniquelli $\mathrm{O}$, et al. Effect of casting technique on surface roughness and constant mass loss after polishing of $\mathrm{NiCr}$ and $\mathrm{CoCr}$ base metal alloys: a comparitive study with titanium". J Prosthet Dent 2004;92(3):274-277. DOI: 10.1016/ j.prosdent.2004.04.021. 
9. Zhang Y, Gou T, Li Z. Effect of mold temperature on the castability of titanium zirconium alloy for dental clinical use. Hua Xi Kou Quang Yi Za Zhi 2001;19(3):178-180.

10. Kitahara K, Kubo F, Takahashi J. Thermal expansion typed investments for casting titanium. Dent Mater J 2004;23(1):1-7. DOI: 10.4012/ dmj.23.1.

11. Fragoso WS, Henriques GE, Contreras EF, et al. The influence of mold temperature on the fit of cast crowns with commercially pure titanium. Braz oral res 2005;19(2):139-143. DOI: 10.1590/S180683242005000200012.

12. Vallitu PK, Lassila VP, Lappalainen R. Transverse strength and fatigue of denture acrylic-glass fiber composite. Dent Mater 1994;10(2): 116-121. DOI: 10.1016/0109-5641(94)90051-5.

13. Jang KS, Youn SJ, Kim YS. Comparison of castability and surface roughness of Commercially pure titanium and cobalt-chromium dentures frameworks. J Prosthet Dent 2001;86(1):93-98. DOI: 10.1067/ mpr.2001.116168.

14. Eliopoulus D, Zinelis S, Papadopoulos T. Porosity of CpTi casting with four different casting machines. J Prosthet Dent 2004;92(4):377-381. DOI: 10.1016/j.prosdent.2004.07.006.

15. Gapido CG, Kobayashi H, Miyakawa O, et al. Fatigue resistance of cast occlusal rests using $\mathrm{Co}-\mathrm{Cr}$ and $\mathrm{Ag}-\mathrm{Pd}-\mathrm{Cu}-\mathrm{Au}$ alloys. J Prosthet Dent 2003;90(3):261-269. DOI: 10.1016/S0022-3913(03)00367-6.

16. Lassida LV, Pekka PK. Effect of water and artificial saliva on the low cycle fatigue resistence of cobalt-chromium dental alloy. J Prosthet Dent 1998;80(6):708-713.

17. Kim DS, Park CJ, Yi YJ, et al. Comparison of cast Ti-Ni alloy clasp retention with conventional removable partial denture clasps. J Prosthet Dent 2004;91(4):374-382. DOI: 10.1016/ j.prosdent.2004.02.015.

18. Dharmar S, Rathnasamy J, Swaminathan TN. Radiographic and metallographic evaluation of porosity defects and grain structure of cast chromium cobalt removable partial dentures. J Prosthet Dent 1993;69:369-373. DOI: 10.1016/0022-3913(93)90182-N.

19. Bridgeman JT, Marker VA, Hummel SK, et al. Comparison of titanium and cobalt-chromium removable partial denture clasps. J Prosthet Dent 1997;78(2):187-193. DOI: 10.1016/S0022-3913(97)70124-0.

20. Morris FH, Asgar K, Brudvik J, et al. Stress relaxation testing. Part IV: Clasp pattern dimensions and their influence on clasp behavior. J Prosthet Dent 1983;50(3):319-326. DOI: 10.1016/S00223913(83)80084-5.

21. Cecconi BT, Koeppen RG, Phoenix RD, et al. Casting titanium partial dental framework. J Prosthet Dent 2002;87(3):277-280. DOI: 10.1067/ mpr.2002.122275.

22. VandenBrink JP, Wolfaardt F, et al. A comparison of various removable partial denture clasp materials and fabrication procedure for placing clasps on canine and premolar teeth. J Prosthet Dent 1993;70(2): 180-188. DOI: 10.1016/0022-3913(93)90016-H.

23. Frank PR, Brudvik SJ, Nicholls IJ. A comparison of the flexibility of wrought wire and cast circumferential clasps. J Prosthet Dent 1983;49(4):471-476. DOI: 10.1016/0022-3913(83)90305-0.

24. Lewis AJ. Radiographic evaluation of porosities in removable partial denture castings. J Prosthet Dent 1978;39(3):278-281. DOI: 10.1016/ S0022-3913(78)80095-X.

25. Ioana B, Wantanabe K, Haruka K, et al. Internal porosity of cast titanium removable partial dentures; influence of sprue direction on porosity of circumferential clasps of a clinical framework design. J Prosthet Dent 2002;88(2):151-158. DOI: 10.1067/mpr.2002. 127400.

26. Yuka K, Atshushi T. Fatigue strength of $\mathrm{Co}-\mathrm{Cr}-\mathrm{Mo}$ alloy clasps prepared by selective laser melting. J Mech Behav Biomed Mater 2016;59:446-458. DOI: 10.1016/j.jmbbm.2016.02.032.

27. Abdul AAK, Murali R. Fatigue behaviour of recasted removable partial denture. Int J Dent Clin 2011;3(4):20-22. 